\title{
Serum levels of VEGF and MCSF in HER2+ / (1) HER2- breast cancer patients with metronomic neoadjuvant chemotherapy
}

\author{
Roberto J. Arai ${ }^{*}$ (D, Vanessa Petry, Paulo M. Hoff and Max S. Mano
}

\begin{abstract}
Metronomic therapy has been gaining importance in the neoadjuvant setting of breast cancer treatment. Its clinical benefits may involve antiangiogenic machinery. Cancer cells induce angiogenesis to support tumor growth by secreting factors, such as vascular endothelial growth factor (VEGF). In breast cancer, Trastuzumab (TZM) based treatment is of key importance and is believed to reduce diameter and volume of blood vessels as well as vascular permeability. Here in we investigated serum levels of angiogenic factors VEGF and MCSF in patients receiving metronomic neoadjuvant therapy with or without TZM. We observed in HER2+ cohort stable levels of MCSF through treatment, whereas VEGF trend was of decreasing levels. In HER2- cohort we observed increasing levels of MCSF and VEGF trend. Overall, HER2+ patients had better pathological response to treatment. These findings suggest that angiogenic pathway may be involved in TZM anti-tumoral effect in the neoadjuvant setting.
\end{abstract}

Keywords: Metronomic chemotherapy, Angiogenesis, Biomarker, Neoadjuvant, Breast cancer

\section{Background}

Neoadjuvant chemotherapy was initially indicated to convert a nonresectable into a resectable lesion $[1,2]$. Data on the efficacy and safety of metronomic chemotherapy in the neoadjuvant setting for breast cancer $(\mathrm{BC})$ is accumulating and supporting application [3-6]. A down staging of operable tumors, allowing for breast-conserving surgery, is also a potential benefit. It is reported that the average response rates - complete response (CR) plus partial response $(\mathrm{PR})$ - and overall clinical benefit $(\mathrm{CR}+\mathrm{PR}+$ stable disease $[\mathrm{SD}]>6$ months) of metronomic chemotherapy in BC management reaches 39\% (range 12-88\%) and $57 \%$ (range $24-93 \%$ ), respectively [7]. The underlying molecular mechanism of clinical benefit, however, still needs clarification. The concept of a treatment that is delivered more frequently with no prolonged drug-free breaks and with low doses has been proven to target tumor angiogenesis, shifting the tumor vasculature [5, 8]. It may increase the antiangiogenic properties of

\footnotetext{
* Correspondence: roberto.arai@hc.fm.usp.br

Departamento de Radiologia e Oncologia, Instituto do Câncer do Estado de São Paulo, Hospital das Clínicas da Faculdade de Medicina da Universidade de São Paulo, CEP 01246-000, Av. Dr. Arnaldo, São Paulo, SP 251, Brazil
}

chemotherapeutic drugs in vitro and in vivo studies [9] including rectal carcinomas [10]. Proliferation and/or induction of apoptosis of activated endothelial cells (ECs) is selectively inhibited as well as inhibition of migration of EC, increase in the expression of thrombospondin-1 and sustained decrease in levels and viability of bone marrow-derived endothelial progenitor cells $[11,12]$. Endothelial toxicity caused by anticancer treatment is not considered an antiangiogenic activity but rather alterations of mechanistic regulators including IL-1 and 6, VEGF, VEGFR1 and 2, bFGF, Ang 1 and 2 and MMP-2 [13]. We previously demonstrated that a neoadjuvant metronomic chemotherapy is feasible in two cohorts of HER2+ and HER2- locally advanced BC patients. The complete pathological response (pCR) rates were 55 and $18 \%$ among patients enrolled in HER2+ and HER2- cohorts, respectively [14]. In the seminal study conducted by Bottini and coworkers, the overall response rate was $71.9 \%$ in the 57 patients randomly assigned to receive primary letrozole and $87.7 \%$ in the 57 patients randomly assigned to receive metronomic letrozole plus cyclophosphamide, respectively. In this study, adverse events were comparable between arms. A significantly greater suppression of Ki-67 and VEGF-A

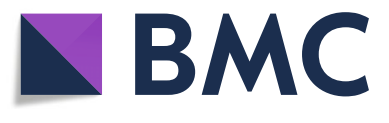

(c) The Author(s). 2018 Open Access This article is distributed under the terms of the Creative Commons Attribution 4.0 International License (http://creativecommons.org/licenses/by/4.0/), which permits unrestricted use, distribution, and reproduction in any medium, provided you give appropriate credit to the original author(s) and the source, provide a link to the Creative Commons license, and indicate if changes were made. The Creative Commons Public Domain Dedication waiver (http://creativecommons.org/publicdomain/zero/1.0/) applies to the data made available in this article, unless otherwise stated. 
expression in the letrozole and cyclophosphamide-treated group compared to the letrozole-only group was found, with a consequent lower Ki-67 and VEGF expression at post-treatment residual histology [3].

TZM is believed to reduce diameter and volume of blood vessels as well as vascular permeability. Studies addressing factors associated with angiogenesis demonstrated that TZM resulted in downregulation of mRNA of the VEGF, transforming growth factor $\alpha$, plasminogen activator inhibitor 1 and angiopoietin 1 while upregulating antiangiogenic factors such as thrombospondin 1 [15]. The mechanism by which TZM coordinates its antitumor activity through angiogenesis pathway is, however, not well understood and need investigations. An important pathway may include signaling factor VEGF. It is suggested as important mediator for transition of pre-invasive to invasive $B C$ [16]. VEGF expression is in turn regulated by MCSF through monocytes to produce biologically active angiogenic factors [17]. Drugs that target VEGF and VEGF receptor made a major impact, however, we have difficulties in identifying which patient would benefit from then [18-20]. A biomarker to predict which patient would benefit from experiencing the most activity and least toxicity would be of scientific relevance. The objective of the present work is to investigate a possible association of angiogenesis machinery of metronomic chemotherapy and TZM treatment in the neoadjuvant setting. For this purpose, we assessed the plasma levels of VEGF and MCSF in BC patients treated in a clinical trial with metronomic neoadjuvant therapy with or without a TZM containing regimen.

\section{Methods}

\section{Study design, participants and sample collection}

Eligible patients required histological confirmation of invasive ductal carcinoma by core biopsy. Patients diagnosed with inflammatory $\mathrm{BC}$ diagnosis were allowed to enter the study. Patients diagnosed with HER2+ BC, defined by HER2 overexpression or amplification, as defined by the American Society of Clinical Oncology/ College of American Pathologist (ASCO/CAP), 2007 HER2 testing guidelines - which was the most widely accepted international guidance by the time the study started [21].

All patients received weekly paclitaxel at $100 \mathrm{mg} / \mathrm{m}^{2}$ for 8 weeks, followed by weekly doxorubicin at $24 \mathrm{mg} /$ $\mathrm{m}^{2}$ for 9 weeks in combination with oral cyclophosphamide at daily dose of $100 \mathrm{mg}$. HER $2+$ group received at loading dose of $4 \mathrm{mg} / \mathrm{kg}$ TZM followed by a maintenance dose of $2 \mathrm{mg} / \mathrm{kg}$ during entire chemotherapy treatment. The total duration of neoadjuvant therapy was 17 weeks. Serum samples were collected from patients at the Instituto do Cancer do Estado de São Paulo (ICESP) included in the clinical research (NCT01329640 and NCT01329627). Prospective sample collections in this phase II study were performed at baseline ( \pm 7 days) from first dose and at each 3 weeks ( \pm 7 days) until week 18. Samples were collected according to institutional Standard Operational Procedures. Briefly, plasma samples were collected in EDTA containing tubes. Samples were incubated $30 \mathrm{~min}$ at room temperature and centrifuged at $1500 \mathrm{~g}$ for $10 \mathrm{~min}$ at $4{ }^{\circ} \mathrm{C}$. Aliquots were then frozen at $-80{ }^{\circ} \mathrm{C}$ until test. Unviable samples such as those with hemolysis were excluded from analysis [22]. Plasma levels of VEGF and MCSF were analyzed by ELISA method according to manufactures' protocol. The ELISA kits were purchased from R \& D Systems.

\section{Statistical analysis}

The chosen method of handling the missing data was the Last Observation Carried Forward (LOCF) [23] as to maintain patient individual response. After run tests we defined that the missing values were not at random. Samples were grouped in weeks $(1 \pm 1$ at week $1,4,7,10$ 13 and 16). Two patients of the HER2- group were excluded from analysis because number of samples collection was $<50 \%$ for each patient. The level of VEGF and MCSF were measured in samples from HER2+ $(n=96)$ and HER2- $(n=108)$ patients. Data were analyzed by using linear regression trend line. Descriptive statistics was used to summarize the results.

Ethical considerations and standards for human research This work has been carried out in accordance with The Code of Ethics of the World Medical Association, Declaration of Helsinki and Good Clinical Practice. The informed consent form was obtained accordingly to current local and international legislation and standards. The privacy rights were granted.

\section{Patients and results}

Twenty patients consented to participate and authorized blood collection. Nine patients expressed HER2 (HER2 + ) and 11 were considered HER2 negative (HER2-). Thirty six percent of patients from HER2- and all patients from HER $2+$ had stage III BC. Of note, 33\% of HER2+ and $66 \%$ of HER2- displayed hormone receptor positivity in tumor tissue (Table 1). HER2+ patients receiving TZM presented a pCR rate of $55,5 \%$ vs $18 \%$ for HER2- patients (Table 2).

\section{VEGF and MCSF determination}

Serum samples were submitted to VEGF and MCSF determination by using Elisa Kit (R\&D Systems). VEGF basal levels were found to be higher in HER2- cohort (Fig 1b). In HER2+ cohort were observed a trend of stable levels of serum MCSF, ranging from $(50 \mathrm{pg} / \mathrm{mL}$ to $450 \mathrm{pg} / \mathrm{mL}$ approximately) (Fig 2a) whereas VEGF levels 
Table 1 Enrolled patients characteristics

\begin{tabular}{lll}
\hline Study group & & Patients \\
\hline Breast cancer & Adenocarcinoma & 20 \\
& & 47,5 \\
Median age (range) & IIA & $(32-69)$ \\
Clinical status & IIB & 1 \\
& III & 3 \\
& IIIB & 12 \\
Histologic grade & IIC & 3 \\
& 1 & 1 \\
HER2 status & 2 & 1 \\
ER status & 3 & 8 \\
PR status & positive & 11 \\
& negative & 9 \\
& positive & 11 \\
& negative & 11 \\
& unknown & 8 \\
& positive & 1 \\
& negative & 13 \\
M & & 7 \\
\hline
\end{tabular}

were found slightly decreasing trend through TZM treatment (Fig 1a). In the HER2- cohort, we found an increasing trend for both VEGF and MCSF levels during treatment (Fig. 1 and 2).

\section{Discussion}

One important scientific appeal of neoadjuvant chemotherapy is the possibility for analyzing the impact of systemic therapy in different $\mathrm{BC}$ subtypes, because tumor tissue biopsies can be obtained at different times during treatment, allowing for the development of biomarkers [8]. In this particular scenario, we were able to collect serum samples and analyze serum markers that might indicate the involvement of angiogenesis pathway in patients with known pathological response.

In the HER2+ cohorts under metronomic therapy with TZM, we observed higher PCR rates and downregulation of the proangiogenic factor VEGF. The ELISA kit used to determine VEGF levels is specific to detect soluble VEGF $_{165}$ and VEGF $_{121}$ among four isoforms

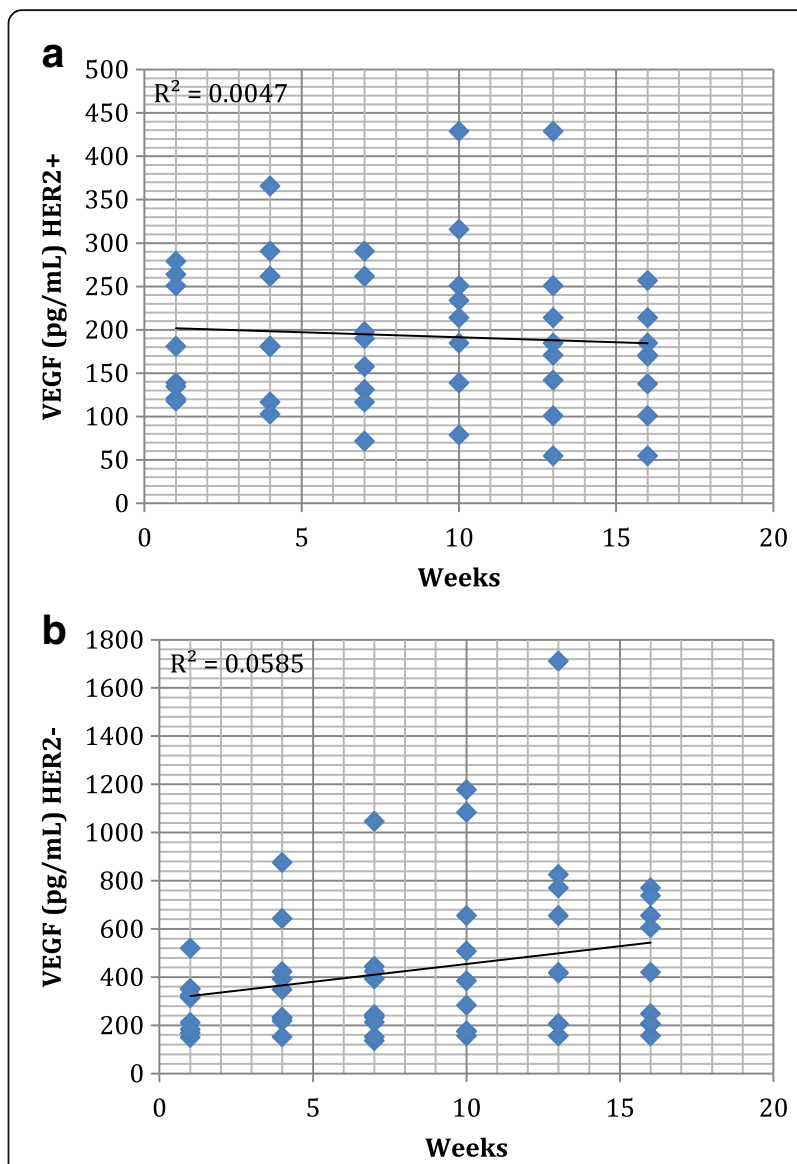

Fig. 1 Table (a) Two-way scatter plots of VEGF serum levels $(n=96)$ in HER2 + patients and (b) HER2- patients $(n=108)$. Trend line along with $R^{2}$ values is shown for each graph

(including bound $\mathrm{VEGF}_{189}$ and $\mathrm{VEGF}_{206}$ ). Thus the levels are indicative of the total circulating VEGF. Our findings corroborate previous observations indicating higher total soluble levels of VEGF in ductal carcinomas $[24,25]$. TZM-treated group showed decreasing levels of VEGF during treatment which is in line with observations described by other groups. Since an activation of HER2-/neu has already been shown to increase the production of VEGF $[15,26]$, studies have suggested an inhibition of angiogenesis in BC by modulation of different (pro and anti) angiogenic factors due to TZM treatment [27]. Metronomic chemotherapy itself would

Table 2 Response to treatment

\begin{tabular}{llll}
\hline Group $(\mathrm{n})$ & Treatment & Complete pathological response (pCR) & Outcome description \\
\hline HER2+ [9] & $\begin{array}{l}\text { Paclitaxel } \\
\text { Doxorubicin } \\
\text { Cyclophosphamide and TZM }\end{array}$ & $55,5 \%$ & $\begin{array}{l}\text { Five patients were alive with no evidence of disease recurrence; } \\
\text { Three patients had disease recurrence; One patient deceased } \\
\text { with disease progression (median follow-up 33.6 months) }\end{array}$ \\
HER2- [11] & $\begin{array}{l}\text { Paclitaxel } \\
\text { Doxorubicin } \\
\text { Cyclophosphamide }\end{array}$ & $\begin{array}{l}\text { Four patients had systemic disease recurrence; one patient } \\
\text { deceases with disease progression; two patients were under } \\
\text { palliative care; seven patients lived with no evidence of disease } \\
\text { recurrence (median follow-up 36.1 months) }\end{array}$ \\
\hline
\end{tabular}



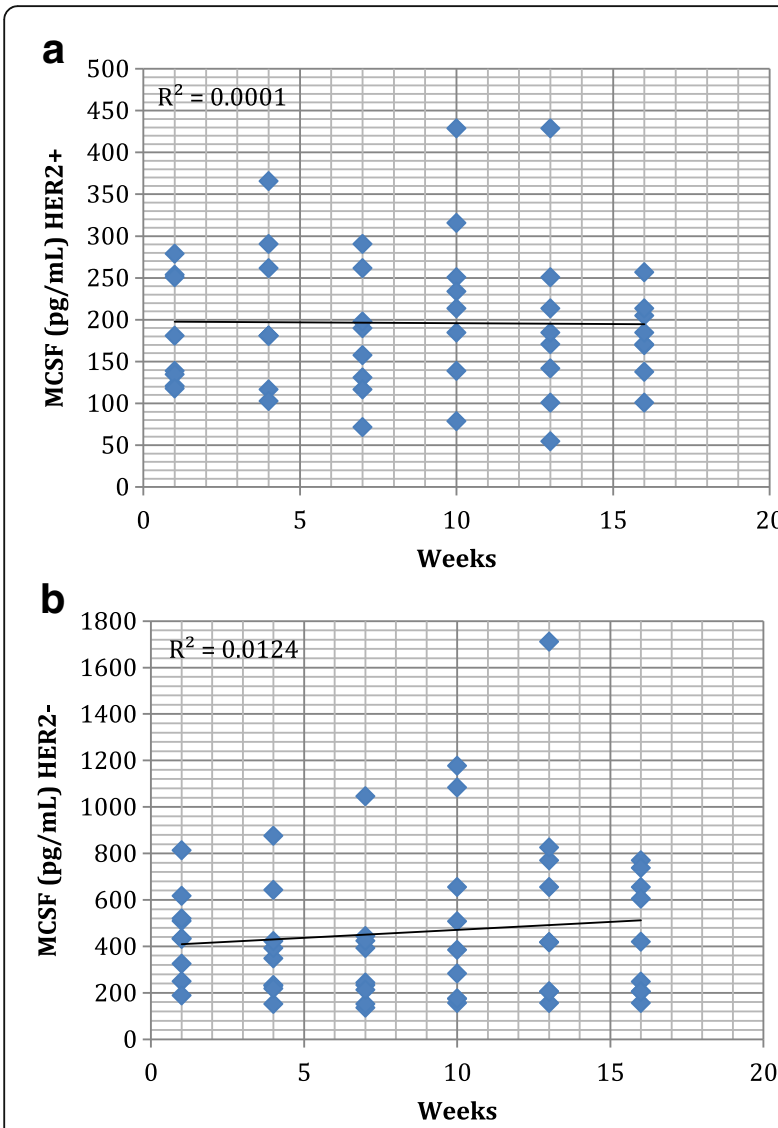

Fig. 2 Table (a) Two-way scatter plots of MCSF serum levels in HER2 + patients $(n=96)$ and $(\mathbf{b})$ HER2- patients $(n=108)$. Trend line along with $R^{2}$ values is shown for each graph

lead to abrogation of newly formed tumor micro vessels and may synergistically impede its formation via downregulation of VEGF signaling promoted by TZM $[28,29]$. Alternatively, the possible VEGF involvement in HER2+ patients under TZM treatment might be related to HER2 + biology per se, without interference of TZM activity; however, this hypothesis could be better understood with a randomized trial design. Our single arm trial design does not allow us to discriminate treatment from disease-related biology effects. Therefore, our work should be viewed as a hypothesis generating study only.

While most of our efforts to date have focused on its antiangiogenic properties, VEGF also has an immunologic role, inducing accumulation of immature dendritic cells, myeloid-derived suppressor cells, and regulatory $\mathrm{T}$ cells, and inhibiting the migration of $\mathrm{T}$ lymphocytes to tumor site [30]. The addition of metronomic chemotherapy to anti-HER2 treatment with TZM and Pertuzumab improve progression free survival in the elderly [31]. One possible mechanism may also involve immunosuppression through downregulation of regulatory $\mathrm{T}$ cells, enhancing antibody-dependent cell mediate cytotoxicity $[31,32]$. In fact, abrogation of immunobiological responses has been seen in patients treated with anti-VEGF therapy [33]. Moreover, chemotherapy typically generates reactive oxygen species in targeted ECs, which can affect angiogenesis. Thus, BC angiogenesis is driven by multiple aspects that probably go well beyond the VEGF.

The anti-VEGF hypothesis in $\mathrm{BC}$ is difficult to reconcile with data from gastric cancer, for instance [34]. This may be explained in part because it is currently unknown which population would benefit from anti-VEGF therapy in BC. Studies examining anti-VEGF therapy in $\mathrm{BC}$ have been probed at both the genomic and proteomic levels [20]. However, to date no prospective trial using biomarkers approach has been published. Further evaluation of metronomic chemotherapy in combination with antiangiogenic agents could be an attractive strategy, although complicated by the fact that bevacizumab has failed clinical trials in the adjuvant setting in both HER2+ [35] and HER2- [36]. Bevacizumab program in this setting is now closed. Similarly, other antiangiogenic agents such as ramucirumab have failed in HER2-, in a $\mathrm{BC}$ randomized trial [37]. These results do not invalidate the strategy, but rather need to narrow targets to test hypothesis.

In our study, we did not observe down-regulation in VEGF or MCSF levels in HER2- patients under metronomic therapy. In a way, our data corroborate data from AVEREL study, a Phase III trial to evaluate bevacizumab in combination with TZM plus docetaxel for HER2 + advanced BC, that showed that a larger bevacizumab treatment effect was observed in patients with high baseline VEGF-A than in those with low VEGF-A [38]. The high local concentration of endothelial-cell survival factors such as VEGF and angiopoietin might cause further chemotherapy efficacy, being one possible mechanism of acquired resistance [39, 40]. The role of angiogenesis in chemo-resistance to TZM in advanced stages is one interesting topic for further investigation since validated biomarker to select potential responders does exist.

Here in we demonstrated potential evidence of angiogenic pathway involvement in the cancer biology of HER2+ patients under metronomic anti-EGF therapy. The sample size, the design of our work, in addition to the unexpected premature termination of the trial, prevents us from drawing firm conclusions. Further studies will be needed to validate our findings.

\section{Abbreviations}

ASCO: American Society of Clinical Oncology; BC: Breast Cancer; CAP: College of American Pathologists; CR: Complete Response; EC: Endothelial Cell;

ELISA: Enzyme-Linked Immunosorbent Assay; FGF 2: Fibroblast Growth Factor 2; HER2: Human Growth Factor Receptor 2; ICESP: Instituto do Cancer do

Estado de São Paulo; LOCF: Last Observation Carried Forward; MCSF: Macrophage Colony Stimulating Factor; MMP2: Matrix Metalloproteinase 2; pCR: Complete

Pathological Response; PR: Partial Response; SD: Stable Disease; TZM: Traztuzumab; 
VEGF: Vascular Endothelial Growth Factor; VEGFR: Vascular Endothelial Growth Factor Receptor

\section{Acknowledgements}

We are thankful to Luciane de Freitas for secretarial support.

\section{Funding}

This work received financial support provided by Brazilian National Council of Scientific and Technology Development, CNPq.

\section{Availability of data and materials}

Data sharing is not applicable to this article.

\section{Authors' contributions}

RJA carried out serum tests, data analysis, and protocol design and manuscript preparation; VP carried out patient treatment and data collection; PMH carried out manuscript preparation and revision; MSM carried out patient monitoring, protocol design and manuscript preparation, All authors read and approved the final manuscript.

\section{Ethics approval and consent to participate}

This work has been carried out in accordance with The Code of Ethics of the World Medical Association, Declaration of Helsinki, and Good Clinical Practice. This work was approved by the Ethics Committee of the Medical School of Medicine, University of Sao Paulo. The informed consent form was obtained accordingly to the current local and international legislation and standards. All patients consent to participate in this study.

\section{Consent for publication}

All patients included in this study consent to publish results. All data were anonymized as to protect individual identity as per Good Clinical Practice.

\section{Competing interests}

The authors declare that they have no competing interests.

\section{Publisher's Note}

Springer Nature remains neutral with regard to jurisdictional claims in published maps and institutional affiliations.

Received: 4 September 2017 Accepted: 30 May 2018

Published online: 14 June 2018

\section{References}

1. Schwartz GF, Birchansky CA, Komarnicky LT, Mansfield CM, Cantor RI, Biermann WA, et al. Induction chemotherapy followed by breast conservation for locally advanced carcinoma of the breast. Cancer. 1994 73(2):362-9.

2. Danforth DN Jr, Lippman ME, McDonald H, Bader J, Egan E, Lampert M, et al. Effect of preoperative chemotherapy on mastectomy for locally advanced breast cancer. Am Surg. 1990;56(1):6-11.

3. Bottini A, Generali D, Brizzi MP, Fox SB, Bersiga A, Bonardi S, et al. Randomized phase II trial of letrozole and letrozole plus low-dose metronomic oral cyclophosphamide as primary systemic treatment in elderly breast cancer patients. J Clin Oncol. 2006;24(22):3623-8.

4. Dellapasqua S, Mazza M, Rosa D, Ghisini R, Scarano E, Torrisi R, et al. Pegylated liposomal doxorubicin in combination with low-dose metronomic cyclophosphamide as preoperative treatment for patients with locally advanced breast cancer. Breast. 2011;20(4):319-23.

5. Munzone E, Colleoni M. Metronomics in the neoadjuvant and adjuvant treatment of breast cancer. Cancer Lett. 2017;400:259-66.

6. Wong NS, Buckman RA, Clemons M, Verma S, Dent S, Trudeau ME, et al. Phase I/II trial of metronomic chemotherapy with daily dalteparin and cyclophosphamide, twice-weekly methotrexate, and daily prednisone as therapy for metastatic breast cancer using vascular endothelial growth factor and soluble vascular endothelial growt. J Clin Oncol. 2010;28(5): 723-30.

7. Pasquier $\mathrm{E}$, Kavallaris M, André N. Metronomic chemotherapy: new rationale for new directions. Nat Rev Clin Oncol. 2010;7:455-65.

8. Emmenegger U, Francia G, Shaked Y, Kerbel RS. Metronomic chemotherapy: principles and lessons learned from applications in the treatment of metastatic prostate cancer. Recent Results Cancer Res. 2010;180:165-83.
9. Munoz R, Shaked Y, Bertolini F, Emmenegger U, Man S, Kerbel RS. Antiangiogenic treatment of breast cancer using metronomic low-dose chemotherapy. Breast. 2005;14(6):466-79.

10. Loven D, Be'ery E, Yerushalmi R, Koren C, Sulkes A, Lavi I, et al. Daily lowdose/continuous capecitabine combined with neo-adjuvant irradiation reduces VEGF and PDGF-BB levels in rectal carcinoma patients. Acta Oncol (Madr). 2008:47(1):104-9.

11. Bocci G, Nicolaou KC, Kerbel RS. Protracted low-dose effects on human endothelial cell proliferation and survival in vitro reveal a selective antiangiogenic window for various chemotherapeutic drugs. Cancer Res. 2002;62:6938-43.

12. Pasquier $E$, André N, Braguer D. Targeting microtubules to inhibit angiogenesis and disrupt tumour vasculature: implications for cancer treatment. Curr Cancer Drug Targets. 2007;7(6):566-81.

13. Ławicki S, Zajkowska M, Głażewska EK, Będkowska GE, Szmitkowski M. Plasma levels and diagnostic utility of VEGF, MMP-9, and TIMP-1 in the diagnosis of patients with breast cancer. Onco Targets Ther. 2016;9:911-9.

14. Petry V, Gagliato DM, Leal AIC, Arai RJ, Longo E, Andrade F, et al. Metronomic chemotherapy in the neoadjuvant setting: results of two parallel feasibility trials (TraQme and TAME) in patients with HER2+ and HER2??? Locally advanced breast cancer. Brazilian J Med Biol Res. 2015;48(5): 479-85.

15. Izumi $Y, X u$ L, di Tomaso E, Fukumura D, Jain RK. Tumour biology: herceptin acts as an anti-angiogenic cocktail. Nature. 2002;416(6878):279-80. Available from: https://doi.org/10.1038/416279b

16. Rice A, Quinn CM. Angiogenesis, thrombospondin, and ductal carcinoma in situ of the breast. J Clin Pathol. 2002;55:569-74.

17. Eubank TD, Galloway M, Montague CM, Waldman WJ, Marsh CB. M-CSF induces vascular endothelial growth factor production and angiogenic activity from human monocytes. J Immunol. 2003;171(5):2637-43.

18. Motzer RJ, Hutson TE, Tomczak P, Michaelson MD, Bukowski RM, Rixe O, et al. Sunitinib versus Interferon Alfa in Metastatic Renal-Cell Carcinoma. N Engl J Med. 2007;356(2):115-24.

19. Escudier B, Eisen T, Stadler WM, Szczylik C, Oudard S, Siebels M, et al. Sorafenib in Advanced Clear-Cell Renal-Cell Carcinoma. N Engl J Med. 2007; 356(2):125-34.

20. Schneider BP, Wang M, Radovich M, Sledge GW, Badve S, Thor A, et al. Association of Vascular Endothelial Growth Factor and Vascular Endothelial Growth Factor Receptor-2 Genetic Polymorphisms With Outcome in a Trial of Paclitaxel. J Clin Oncol. 2008;26(28):4672-8.

21. Wolff AC, Hammond MEH, Schwartz JN, Hagerty KL, Allred DC, Cote RJ, et al. American Society of Clinical Oncology/College of American Pathologists guideline recommendations for human epidermal growth factor receptor 2 testing in breast cancer. J Clin Oncol. 2007;25(1):118-45.

22. Tuck MK, Chan DW, Chia D, Godwin AK, Grizzle WE, Krueger KE, et al. Standard operating procedures for serum and plasma collection: early detection research network consensus statement standard operating procedure integration working group. J Proteome Res. 2009;8(1):113-7.

23. Kang $\mathrm{H}$. The prevention and handling of the missing data. Korean J Anesth. 2013;64:402-6

24. Dvorak HF, Brown LF, Detmar M, Dvorak AM. Vascular permeability factor/ vascular endothelial growth factor and the significance of microvascular hyperpermeability in angiogenesis. Am J Pathol. 1999:149(5):1029-39.

25. Heer K, Kumar H, Read JR, Fox JN, Monson JR, Kerin MJ. Serum vascular endothelial growth factor in breast cancer: its relation with cancer type and estrogen receptor status. Clin Cancer Res [Internet]. 2001;7(11):3491-4.

26. Yen L, Benlimame N, Nie Z-R, Xiao D, Wang T, Al Moustafa A-E, et al. Differential regulation of tumor angiogenesis by distinct ErbB homo- and heterodimers. Mol Biol Cell. 2002;13(11):4029-44.

27. Lange T, Nentwich MF, Lüth M, Yekebas E, Schumacher U. Trastuzumab has antimetastatic and anti-angiogenic activity in a spontaneous metastasis xenograft model of esophageal adenocarcinoma. Cancer Lett. 2011;308(1):54-61.

28. Browder T, Butterfield CE, Kräling BM, Shi B, Marshall B, O'Reilly MS, et al. Antiangiogenic scheduling of chemotherapy improves efficacy against experimental drug-resistant cancer. Cancer Res. 2000;60(7):1878-86.

29. Kerbel RS, Kamen BA. The anti-angiogenic basis of metronomic chemotherapy. Nat Rev Cancer. 2004;4(6):423-36.

30. Voron T, Marcheteau E, Pernot S, Colussi O, Tartour E, Taieb J, et al. Control of the Immune Response by Pro-Angiogenic Factors. Front Oncol. 2014;4:70.

31. Wildiers H, Tryfonidis K, Dal Lago L, Vuylsteke P, Curigliano G, Waters S, et al. Pertuzumab and trastuzumab with or without metronomic chemotherapy 
for older patients with HER2-positive metastatic breast cancer (EORTC 75111-10114): an open-label, randomised, phase 2 trial from the Elderly Task Force/Breast Cancer Group. Lancet Oncol. 2018;(3):323-36.

32. Kalsi T, Babic-IIIman G, Fields P, Hughes S, Maisey N, Ross P, et al. The impact of low-grade toxicity in older people with cancer undergoing chemotherapy. Br J Cancer. 2014;111(12):2224-8.

33. Osada T, Chong G, Tansik R, Hong T, Spector N, Kumar R, et al. The effect of anti-VEGF therapy on immature myeloid cell and dendritic cells in cancer patients. Cancer Immunol Immunother. 2008;57(8):1115-24.

34. Sledge GW, Alto P. Anti - Vascular Endothelial Growth Factor Therapy in Breast Cancer: Game Over? J. Clin Oncol. 2015;33(2):133-5

35. Slamon DJ, Swain SW, Buyse M, Martin M, Geyer CE, Im YH, Pienkowski T, Kim SB, Robert NJ, Steger G, Crown J, Verma S, Eiermann W, Costantino JP, Im SA, Mamounas EP, Schwartzberg L, Paterson A, Mackey JR, Provencher L, Press MF, Thirlwell M, Bee-Munte V C-F a and W. Primary results from BETH, a phase 3 controlled study of adjuvant chemotherapy and trastuzumab \pm bevacizumab in patients with HER2-positive, node-positive or high risk node-negative breast cancer. Cancer Res 2013;73(24suppl):s1-s3.

36. Cameron D, Brown J, Dent R, Jackisch C, Mackey J, Pivot X, et al. Adjuvant bevacizumab-containing therapy in triple-negative breast cancer (BEATRICE): primary results of a randomised, phase 3 trial. Lancet Oncol. 2013;14(10): 933-42.

37. Mackey JR, Ramos-Vazquez M, Lipatov O, McCarthy N, Krasnozhon D, Semiglazov V, et al. Primary results of ROSE/TRIO-12, a randomized placebocontrolled phase III trial evaluating the addition of ramucirumab to first-line docetaxel chemotherapy in metastatic breast cancer. J Clin Oncol. 2015; 33(2):141-8

38. Gianni L, Romieu GH, Lichinitser M, Serrano SV, Mansutti M, Pivot X, et al. AVEREL: a randomized phase III trial evaluating bevacizumab in combination with docetaxel and trastuzumab as first-line therapy for HER2positive locally recurrent/metastatic breast cancer. J Clin Oncol. 2013;31(14): 1719-25.

39. Sweeney CJ, Miller KD, Sissons SE, Nozaki S, Heilman DK, Shen J, et al. The antiangiogenic property of docetaxel is synergistic with a recombinant humanized monoclonal antibody against vascular endothelial growth factor or 2-methoxyestradiol but antagonized by endothelial growth factors. Cancer Res. 2001;61 (8):3369-72.

40. Tran J, Master Z, Yu JL, Rak J, Dumont DJ, Kerbel RS. A role for survivin in chemoresistance of endothelial cells mediated by VEGF. Proc Natl Acad Sci U S A. 2002;99(7):4349-54.

\section{Ready to submit your research? Choose BMC and benefit from:}

- fast, convenient online submission

- thorough peer review by experienced researchers in your field

- rapid publication on acceptance

- support for research data, including large and complex data types

- gold Open Access which fosters wider collaboration and increased citations - maximum visibility for your research: over $100 \mathrm{M}$ website views per year 